\title{
Un trastorno posmoderno (psicología, sociedad y déficit de atención) ${ }^{1}$
}

\section{A posmodern disorder (psychology, society and attention deficit disorder)}

Héctor Eduardo Robledo Mejía

Universitat Autónoma de Barcelona

chacsol@gmail.com

\begin{abstract}
Resumen
La creciente detección del Trastorno por Déficit de Atención con Hiperactividad (TDA-H) en infantes tiene lugar en una sociedad que identifica su pensamiento y comportamiento con las reacciones químicas de su cerebro, por lo que encuentra la explicación a todos sus desórdenes en el malfuncionamiento de éste. La psicología social permite una versión alternativa acerca de este trastorno.
\end{abstract}

Palabras clave: Trastorno por Déficit de Atención con Hiperactividad, determinismo biológico, pensamiento, comportamiento, psicología social.

Keywords: Attention Deficit Disorder, biologic determinism, thought, behavior, social psychology

Si su hijo presenta excesiva inquietud motora, dificultades de aprendizaje escolar, molesta frecuentemente a otros niños, se distrae fácilmente, exige inmediata satisfacción a sus demandas, tiene dificultades para cooperar, está en las nubes, es irrespetuoso, es intranquilo, es impulsivo, le falta sentido del juego limpio, es irritable... seguramente tiene Trastorno por Déficit de Atención con Hiperactividad (TDA-H), que además es el trastorno más diagnosticado en niños en edad escolar en sociedades como la estadounidense, la canadiense, la chilena, la colombiana y la mexicana. Entre el 6 y el 10\% de esta población, según los especialistas, lo padece, aunque en Colombia la cifra es hasta del 18\% (periódico La Jornada, 11/ 10/ 02), con lo cual no faltará quien esté ya haciendo hipótesis de por qué ese país está como está.

Los neurocientíficos aceptan que las pruebas actuales todavía no permiten identificar un mal funcionamiento cerebral asociado de manera específica al TDA-H, pero esperan que en un futuro se disponga de instrumentos y métodos que lo pongan de manifiesto. Estas "incertidumbres" han traído

1 Puedes acceder a un vídeo relacionado con este artículo en http://www.archive.org/details/Hiperactividad 
consigo una candente polémica en cuanto al tratamiento del TDA-H. La más sonada es la de la medicación.

Existen productos farmacéuticos para tratar el TDA-H. El más conocido y discutido es el Metilfenidato, que en México y muchos otros países es vendido como Ritalín. Se dice que sus efectos inmediatos son un aumento de la capacidad de atención y concentración y una reducción de la hiperactividad y la movilidad del niño. No hay acuerdo total sobre este tipo de tratamiento, pero llega a ser impuesto por las instituciones educativas ("si el niño no viene medicado no entra") por lo que existen fuertes reclamos de diversos sectores sociales implicados en el problema argumentando que el famoso Ritalín está convirtiendo a los niños en zombies y a las empresas farmacéuticas en multimillonarias.

\section{Puro cuento}

Cuando se dice que algo es "puro cuento", es porque seguramente se está tratando de argumentar mitos. Lo cierto es que todo pensamiento, ya sea religioso, científico o cotidiano tiene una estructura mítica interna (Fernández Christlieb, 2001). Es decir que toda realidad se cimienta en un cuento, en un mito, que por alguna razón se encuentra ya en el pensamiento de la sociedad.

La psicología social propone que todas las cosas que llenan nuestro mundo son construcciones de sociedades concretas. Aquí no se trata entonces de contestar a la pregunta de si el TDA-H es "realmente" un trastorno neurológico o pura conspiración de transnacionales farmacéuticas. Tampoco intentar negarlo, sino "explorar las diversas maneras de construir y socavar su realidad" (Potter, 1996 [1998], p. 20), que sólo existe cuando es pensada por la sociedad, y para ello es preciso destacar su insoslayable dimensión histórica (Ibáñez, 1990 [2001], p. 217).

\section{La tradición del determinismo biológico}

Uno pensaría que no tiene por qué dudar de la investigación neurocientífica. Por supuesto que no, cuando una sociedad tiene varios siglos pensando que el órgano del comportamiento es el cerebro. Curiosamente no siempre ha sido así: hubo sociedades en que de veras la gente actuaba "de corazón"; otras pensaron con los riñones, y hasta con la sangre (Fernández Christlieb, 2002). A diferencia de la Edad Media, en la que la vida era concebida como un mundo estático de relaciones sociales legitimadas por Dios, en la que los hechos no tenían porqué ser coherentes y la enfermedad podía ser un fenómeno natural por derecho propio o una visitación del Señor, la modernidad fragmentó todo, incluyendo al cuerpo humano, el cual fue equiparado a la máquina y dividido en mecanismos, con su control central en el cerebro. Es ésta la tradición del determinismo biológico que permea aun hoy las ciencias del comportamiento. Es el paradigma hegemónico, y así ha sido perpetuado en el lenguaje que utilizamos cotidianamente: “¿dónde tienes la cabeza?", "eres un cabeza hueca", "tienes problemas en el cerebro", "tienes mucho seso", etc.

Moleschott en el siglo XIX, ya en la lógica cartesiana, afirmó que el cerebro segrega pensamiento como el riñón secreta orina. También la conciencia había de ponerse en términos físicoquímicos. Para tal objetivo se hizo necesario disponer de una teoría del comportamiento, "el cual ya no era considerado como un flujo continuo y sólo en parte predecible de acción humana que surgía de las exigencias del alma, del libre albedrío y de los caprichos del carácter humano, materia más apta para el novelista que para el científico" (Kamin, Lewontin y Rose, 1984 [1987], p. 70).

Ya en el siglo XX, se estudiaron cerebros famosos post mortem, como los de Lenin, Trotsky y Einstein. De hecho, el cerebro de Lenin tuvo un instituto creado especialmente para su análisis, pero parece que no hubo preguntas razonables que le pudiera dirigir a un cerebro, sin importar que tan distinguido fuera Lenin. Hasta ahora la neuropsicología puede decir cuándo uno está pensando, soñando o recordando, pero no puede decir qué.

Sucedió también que para estudiar la mente humana la psiquiatría se apoyó en las neurociencias y se preocupó más por la psicobiología y la psicofisiología, olvidándose del psicoanálisis; la psicología se empapó de cognitivismo, y tomó como conceptos y objetos de estudio la percepción, la memoria, la atención y con ello la falta de atención. Y qué decir de la industria farmacéutica, que año con año incrementa la venta de productos para tratar el TDA-H, ni modo de no 
publicitar la existencia del trastorno. ¿Por qué cuestionarlo? Si el sustrato del pensamiento y el comportamiento está en el cerebro, el cual es un continuo de reacciones químicas, lo más lógico es que el problema sea atacado con medicamentos.

¿Pero qué tal que el paradigma hegemónico para comprender el comportamiento humano fuera el de las ciencias de la cultura, o del Espíritu, como la Volkerpsychologie (o psicología de los pueblos como suele traducirse) desarrollada en la segunda mitad del siglo XIX? Ésta considera que la sociedad es un ente pensante en sí misma, que los individuos están dentro del pensamiento de la sociedad y no al revés, y que el órgano con el que ésta piensa es el lenguaje y no el cerebro, como ya propusiera Steinthal en la primera cátedra de psicología en el mundo, en 1860.

Es decir que a través del lenguaje una sociedad se pone de acuerdo en que quien dirige su comportamiento es su cerebro, su sangre o su corazón. Alguien podría decir que si la Volkerpsychologie no es el paradigma hegemónico para explicar el comportamiento humano, es porque cuenta con los argumentos suficientes para serlo. $Y$ puede que tuviera razón: la Volkerpsychologie prácticamente murió a principios del siglo XX porque sus argumentos no iban con la corriente positivista de su época que quería hacer de la psicología una ciencia experimental, para que fuera ciencia, claro. Y que una sociedad piense con el lenguaje no es algo que se pueda demostrar en el laboratorio, por lo tanto para la ciencia positivista eso no puede ser "real". La realidad es un asunto de retórica, o sea de quien tenga mejores argumentos en determinado momento histórico (Potter, op. cit.).

Si tomamos la perspectiva de la psicología del espíritu colectivo (que podemos llamar Volkerpsychologie, psicología colectiva, psicología social o como se quiera) se puede contrariar a la historia oficial del TDA-H que considera que éste siempre ha existido, pero es a últimas fechas que fue descubierto dado el avance de la investigación científica. En lugar de considerar el trastorno "dentro del contexto de un fenómeno biológico en el acto de ser descubierto, [podemos] examinarlo simplemente como una corriente histórica con vida y dirección propia. En este contexto, podríamos contemplar al ADD/ ADHD [siglas en inglés del TDA-H] como un fenómeno relativamente reciente que hizo irrupción en la escena estadounidense en los últimos quince años como resultado de determinados procesos sociales" (Armstrong, 1999, p. 36). Y las sociedades latinoamericanas de tanto insistir en medirse con los modelos gringos para parecernos cada vez más a ellos, hemos importado hasta sus trastornos, desde el momento en que trajimos sus ciencias médicas y psicológicas, pero sobre todo sus formas de entretenimiento, de consumir la salud y de funcionar socialmente.

Hasta hace muy poco tiempo los profesionales de la educación y campos afines atribuían las características hoy asociadas al TDA-H, a un reducido número de niños. Pero desde la aparición del Manual de diagnóstico y estadística (DSM por sus siglas en inglés) de la Asociación Psiquiátrica Americana en 1968, se ha ido cambiando la denominación y categoría diagnóstica a las características asociadas con el TDA-H. A niños con las mismas características se les ha asignado como media docena de rótulos distintos. Aparecen y desaparecen diversos criterios para diagnosticar sus variantes. (Armstrong, 1999 [2001], p. 37). Cada vez caben más niños en la categoría de trastornados.

\section{Medios informativos y paradojas posmodernas.}

Los teóricos de la posmodernidad afirman que la realidad es una construcción social. Quizá tengan razón. Es social porque se intercambia a través del lenguaje, en la comunicación. Pero en cierto sentido la realidad cada vez menos es construcción colectiva porque no es ya acordada en la comunicación, sino que es impuesta por la fuerza de la imagen televisiva y demás medios informativos electrónicos, que nos obsequian la realidad procesada. Sí, a las palabras y los acuerdos se los llevó el viento. Ya no se discute por estar mirando el aparato. La comunicación, en ese sentido, está rota. Quienes tienen la palabra en la pantalla son los especialistas, y parece que en tanto más aceptamos sus opiniones sobre la realidad, más nos encontramos lejos de ella.

A través de los medios, Guido Belssaso, antes comisionado del Consejo Nacional contra las Adicciones y Salud Mental de la Secretaría de Salud, aseveró que al menos 1.5 millones de infantes viven con el TDA-H en México, que ya son años de investigación científica sobre éste y los resultados con el metilfenidato son satisfactorios. Por supuesto él tiene su clínica privada donde atenderlos. Otros discursos mediáticos indican que como el TDA-H no es diagnosticado más que con la 
observación del comportamiento, a cualquier niño se le "ritaliniza" con causas ajenas a un trastorno neurobiológico. Así fue denunciado por el periodista Ricardo Rocha en México (2001), el cual presentó en televisión entrevistas con niños y niñas que habían sido medicados con Ritalín, y decían haber sufrido dolores de cabeza, mucho sueño, ganas de hacer nada. Sus madres argumentaban que se había anulado por completo la actividad normal de sus hijos. Organizaciones sociales como la Comisión Ciudadana de Derechos Humanos en la Ciudad de México, apuntan a que el TDA-H es una enfermedad inventada como dispositivo de control social, o una estrategia más de grandes laboratorios farmacéuticos para introducir con éxito sus productos en el mercado. Especialmente a partir de este programa comenzó a cundir el pánico en escuelas primarias, de la glorificación el uso del Ritalín pasó a ser satanizado. La comunicación está rota.

Aunque Internet presenta sus alternativas. En la misma proporción que se nos han quitado las ganas de platicar en los parques, nos ha dado por discutir temas de trascendencia en foros cibernéticos. En el portal MSN existe uno que se llama Déficit de Atención. Aquí es donde las mamás comparten semana a semana sus más profundas preocupaciones respecto a sus vástagos hiperactivos. La incertidumbre respecto a la medicación es grande. Hay quienes la defienden, hay quienes la creen innecesaria y quienes opinan que depende de cada caso. Soluciones posmodernas para un mal posmoderno. Enorme diversidad de formas de diagnóstico y tratamiento. Cada quien tiene sus recetas: farmacológicas, alimenticias, terapéuticas, afectivas. Cualquiera tiene la razón y cualquiera podría estar equivocada. Son las supuestas ventajas de la democracia tan defendida por Estados Unidos, que ha llegado a aniquilar hasta el sentido común (cfr. Dufour, 1997).

Por otra parte, como señala Thomas Armstrong, estamos viviendo en una "cultura del tiempo de atención breve", en la que es natural el hecho de que los cerebros sean reprogramados por los medios informativos con sus tiempos de atención breves. Pero más bien lo que está siendo reprogramado son nuestras relaciones con las personas y los objetos, lo que se relaciona con una cultura utilitaria, donde no vale la pena atender a lo que no sirve, y lo que sirve es rápidamente desechable, así que no es necesaria más que una atención muy breve.

\section{Ironías}

Las ciencias médicas y neuropsicológicas, por ser ciencias biológicas, son universales, eso lo tenemos bien sabido. Por eso se dice con precisión que tanto en Estados Unidos como en Colombia, Argentina, Suecia, Japón y México entre el 6 y el 10\% de los niños padece TDA-H. Los ejemplos en nuestra cultura abundan: que Tom Sawyer, el famoso personaje de Mark Twain, es testimonio de que el TDA-H ya existía desde hace tiempo, según los psicólogos españoles Ávila y Polaino Lorente (2002). Bart Simpson ni duda cabe que lo tiene. Pero quién lo hubiera pensado de Winnie Pooh, que fue diagnosticado con TDA-H por pediatras de la Universidad Dalhousie de Halifax, en Canadá (La Jornada, 17/ 10/ 01). Los departamentos criminológicos del Estado español saben que los etarras suelen ser hiperactivos (La Jornada, 14/ 12/ 99). El problema no es psicológico sino orgánico, o dicho de otro modo, los problemas psicológicos son orgánicos. Siempre y cuando el órgano del comportamiento sea el cerebro. Si el pensamiento está en el cerebro, los problemas del comportamiento están ahí, y hay que atacarlos con drogas.

Pero si decimos que la sociedad piensa con el lenguaje, con sus palabras, el asunto se convierte en epistemológico, y en una de esas, lo del TDA-H ni problema es. Después de todo, los especialistas más optimistas piensan que el TDA-H pudiera ser una ventaja adaptativa, la cual aprovechó gente como Edison, Mozart, Einstein, Kennedy y Dustin Hoffman. Si alguien quisiera comprender cómo percibe el mundo un hombre con TDA-H, tal vez habría que ver las películas Amores Perros y 21 gramos, cuyo guionista Guillermo Arriaga, atribuye su pensamiento no lógico y no lineal así como se aprecia en sus obras, a que padece aquel trastorno. Cabe entonces aquí la afirmación del psicólogo social Kenneth Gergen (1992) de que términos como el de TDA-H, al igual que muchos otros que son de uso corriente en las profesiones que se ocupan de la salud mental, para un sector significativo de la población no sirven sólo para describir defectos y anomalías, sino para dar sentido al yo.

En la Escuela Primaria Miguel Domínguez, en México, aproximadamente el 50\% de los alumnos coincide con el diagnóstico TDA-H: se mueven todo el tiempo, se distraen fácilmente ante estímulos externos, tienen dificultad para seguir instrucciones, saltan de una actividad a otra, hablan demasiado, agreden físicamente a sus compañeros y se creen más inteligentes que sus profesores. Coincidentemente la mitad de los alumnos de esta escuela sólo viven con su madre, la cual trabaja 
todo el día. Los que tienen la "bendición" de tener padre es para recibir golpes. Por supuesto que sufren déficit de atención.

La Secretaría de Salud de México ha reconocido el TDA-H como problema de salud pública en el país, por lo que está apoyando capacitación para los profesores de las escuelas públicas como la Miguel Domínguez que les enseñe a lidiar con el trastorno. Ahora ellos saben que sus alumnos con estas características no son desobedientes nada más por que sí, sino porque tienen TDA-H. A la sociedad no le pasa nada. Entonces lo que tendríamos que esperar es que se empiecen a suministrar los medicamentos apropiados de forma gratuita para tener el problema resuelto.

\section{Déficit de pasión}

Aunque el impulso para el desarrollo de teorías deterministas biológicas y de fármacos para el tratamiento de "desórdenes comportamentales" es intenso, esto no puede ser entendido sólo en términos de la necesidad de controlar y pacificar a una indomable población de niños en edad escolar: los sentimientos de alienación y falta de sentido de la vida que experimenta una gran parte de la población norteamericana, pero también cada vez más de la nuestra, es una realidad palpable. Es por eso también que sentimos la necesidad de confiar en que estos problemas pueden ser solventados por las ciencias médicas. "La creciente demanda de los sufridores de algo que alivie su dolor psíquico, y la investigación que efectúen médicos comprensivos para encontrar estas soluciones son poderosos motores. El creciente prestigio de la biología, con sus aparentes certezas deterministas, ofrecen el señuelo teórico" (Kamin, Rose y Lewontin, op. cit.). ¿Qué va a pasar en una sociedad que no ofrece razones para adquirir un curso en la vida sino solamente estímulos, que no tienen otro objeto que el de exhortar al consumo y producir para ello? Si se carece de atención es porque se carece de pasión, ya lo sabían los psicólogos sensistas Helvétius y Condillac en el siglo XVIII.

\section{Referencias}

Armstrong, T. (1999). Síndrome de Déficit de Atención con o sin Hiperactividad ADD/ ADHD. Estrategias en el aula. Buenos Aires: Paidós, 2001.

Ávila, C.; Polaino Lorente, A. (2002), Niños hiperactivos. Madrid: Alfaomega.

Ávila, M. Datos y reflexiones acerca del uso del metilfenidato (ritalín) para el tratamiento del trastorno por déficit de atención e hiperactividad. Revista de la Facultad de Medicina UNAM, Vol. 47 No. 1, enero-febrero 2004.

Dufour, D.-R. (1996). Locura y democracia. Ensayo sobre la forma unaria. México: Fondo de Cultura Económica, 2002.

Fernández Christlieb, P. La sociedad que piensa y qué piensa la sociedad: razones para hacer una psicología colectiva, en Piper, I. (comp.) (2002), Políticas, Sujetos y Resistencias. Debates y Críticas en Psicología Social._Santiago de Chile: ARCIS.

Fernández Christlieb, P. La estructura mítica del pensamiento social. Athenea Digital, No. 0. Abril 2001. http://anthalya.uab.es/athenea/num0/pablo.pdf

Gergen, K. (1992). El yo saturado. Dilemas de identidad en el mundo contemporáneo. Barcelona: Paidós, 1997.

García Pérez, Magaz Lago. Grupo ALBOR-COHS (2001), Página web: www.tda-h.com España.

Ibáñez, T. (1990). Psicología social construccionista. Guadalajara: U. de G., 2001. 
Kamin, L.; Lewontin, C.; Rose, E. (1984). No está en los genes. Barcelona: Crítica, 1987.

Periódico LA JORNADA, Winnie Puh, inspirado en un oso de carne y hueso de Canadá. 17 de octubre de 2001.

Potter, J. (1996). La representación de la realidad. Discurso, retórica y construcción social. Barcelona: Paidós. 1998.

Rocha, R. Programa televisivo Reporte 13. TV Azteca. Septiembre 2001. México.

Secretaría de Salud, Programa de Acción Salud Mental: Programa Específico de Trastornos por Déficit de Atención. México. http://www.ssa.gob.mx/conadic/progesp tda.htm

Soto Ramírez, J. Niños Ritalín, en periódico La Jornada. México, 2 de abril de 2001.

\section{Formato de citación}

Robledo, Héctor Eduardo. (2006). Un trastorno posmoderno (psicología, sociedad y déficit de atención). Athenea Digital, 9. Disponible en http://antalya.uab.es/athenea/num9/Robledo.pdf.

\section{SOCGE RIGHIS RESERVED}

Este texto está protegido por una licencia Creative Commons.

Usted es libre de copiar, distribuir y comunicar públicamente la obra bajo las siguientes condiciones:

Reconocimiento: Debe reconocer y citar al autor original.

No comercial. No puede utilizar esta obra para fines comerciales.

Sin obras derivadas. No se puede alterar, transformar, o generar una obra derivada a partir de esta obra.

\section{Resumen de licencia}

\section{Texto completo de la licencia}

